\title{
Synergetic effect of metal-organic framework UiO-66 and silver plasmonic nanoparticles on PET waste support in degradation of nerve agent simulant
}

\author{
Oleg Semyonova , Dmitry Kogolev ${ }^{\mathrm{a}}$, Andrii Trelin ${ }^{\mathrm{b}}$, Mekhman S. Yusubov $^{\mathrm{a}}$, Olga Guselnikova ${ }^{\mathrm{a}, \mathrm{b}}$ *, \\ Pavel S. Postnikova, ${ }^{\mathrm{a}, *}$
}

\footnotetext{
a Tomsk Polytechnic University, 634050 Tomsk, Russian Federation

${ }^{\mathrm{b}}$ Department of Solid-State Engineering, University of Chemistry and Technology, 16628 Prague, Czech Republic
}

* Corresponding authors: postnikov@tpu.ru (P.S.Postnikov), guselnikovaoa@tpu.ru (O.Guselnikova) 


\begin{abstract}
The combination of versatile metal-organic frameworks (MOFs) with high porosity and catalytic activity with plasmonic nanoparticles (PNPs) defines a new paradigm in photocatalytic degradation of ecotoxicants. Herein, we prepared a novel composite from a waste polyethylene terephthalate, MOF - UiO-66 and silver nanoparticles (AgNPs) for degradation of nerve agent simulant paraoxon-ethyl, where the additional plasmon excitation at $455 \mathrm{~nm}$ enhances Lewis's acid activity of UiO-66. The obtained material was characterized by spectroscopic: XRD, UV-Vis, FT-IR, XPS, microscopic: SEM, TEM and ICP-MS and TGA. We found the balance between pore availability of UiO-66 for paraoxon-ethyl adsorption to Lewis sites, plasmonic enhancement, and cost minimization in optimal material through variation of added Ag precursor amounts PET@UiO-66-Ag25. Synergetic mechanisms enhanced the degradation rate by more than 3 times compared to PET@UiO-66 with the quantitative paraoxon degradation for 1 hour ( $>95 \%$ ) and $>99 \%$ for 2 hours. Moreover, the prepared material is overperforming other materials in terms of environmental impact, easiness of preparation, visible light usage, high apparent quantum yield and recycling performance.
\end{abstract}

\title{
Keywords
}

Metal-organic frameworks; paraoxon-ethyl degradation; polyethylene terephthalate waste; plasmonic degradation; silver nanoparticles. 


\section{Introduction}

Nowadays, the sustainable growth of food production is faced up with broad application of ecotoxicants contaminating the surrounding media [1]. The past and ongoing application of various fungicides, insecticides, herbicides led to accumulation of ecotoxicants in the soil and natural water sources [2]. Despite environmental law enforcement of pesticide application [3], additional solution lays in the design of materials for purification of contaminated water via adsorption and degradation. The most commonly used materials are carbon-based adsorbents [4], clays [5], nanosized $\mathrm{MgO}$ and $\mathrm{TiO}_{2}$ [6,7], and, recently, and recently metal-organic frameworks (MOFs) [8]. Despite MOFs outperform the traditional adsorbents [9], their application is often limited due to the low stability, granulometric composition and high cost $[9,10]$. Such issues can be solved by the implementation of sustainable synthesis strategies for organic ligands and application of relevant support for MOFs. For instance, the MOFs prepared directly from waste PET can be considered as an admirable alternative for traditional sorbents [11].

Nevertheless, the adsorptive methods for the removal of ecotoxicants require the additional stage for the utilization - removal and processing. Due to this reason, the development of strategy for the degradation of ecotoxicants takes central stage in the modern technology [12]. The traditional methods associated with burning of wastes do not fit with the climate changes and necessity of $\mathrm{CO}_{2}$ utilization, while straightforward photolysis and biodegradation need a long reaction time and less efficient [13]. Photochemical degradation is more promising because it requires a renewable source of energy - light, which can be controlled in terms of wavelength and power [14]. For example, $\mathrm{TiO}_{2}$ as the most common photocatalyst can accelerate the degradation of ecotoxicants under energy-consuming UV light despite low surface area materials with wide band gap energies [14,15]. To repel such disadvantages, the metal nanoparticles with zero gap have been applied for the degradation of pesticides, which allow using the less energetic light source and sufficiently increasing the efficacy of ecotoxicants utilization [16]. In spite of that, plasmonic nanoparticles (PNPs) have other technological issues: low surface area, relatively high cost, practical impossibility for recycling and low stability. In order to overcome limitation of MOFs and PNPs and enhance each other in ecotoxicants degradation, we propose to develop the composite material based on PNPs with the plasmon resonance in visible light range [17] combined with high surface area MOFs. The combination of intrinsic MOFs and PNPs properties allow to achieve the synergetic effect for the maximization of efficacy and enhance the technological applicability [14]. 
Here, we aimed at deposition of AgNPs to PET @UiO-66 for the careful engineering of plasmon-active porous materials for the degradation of paraoxon-ethyl as an example of nerve agent $[18,19]$. We studied the degradation efficiency (optimization and further kinetic parameters) of paraoxon-ethyl and found a proper balance between catalytic performance, surface properties and cost for efficient removal and plasmonic degradation via synergetic effect of UiO-66 and AgNPs in the technology-appealed fashion. 


\section{Results and discussion}

We commenced our investigation from the preparation of waste PET-derived adsorbent PET@UiO-66 presenting polymer chips coated by porous UiO-66 (brief characterization by SEM(EDX), FTIR, UV-Vis and XRD is represented in Fig. S1). Further, AgNPs were deposited to the PET@UiO-66 via in situ chemical reduction for preparation of plasmonic system, where visible light irradiation could act together with the porous layer for effective energy transfer between catalytic MOFs and AgNPs.

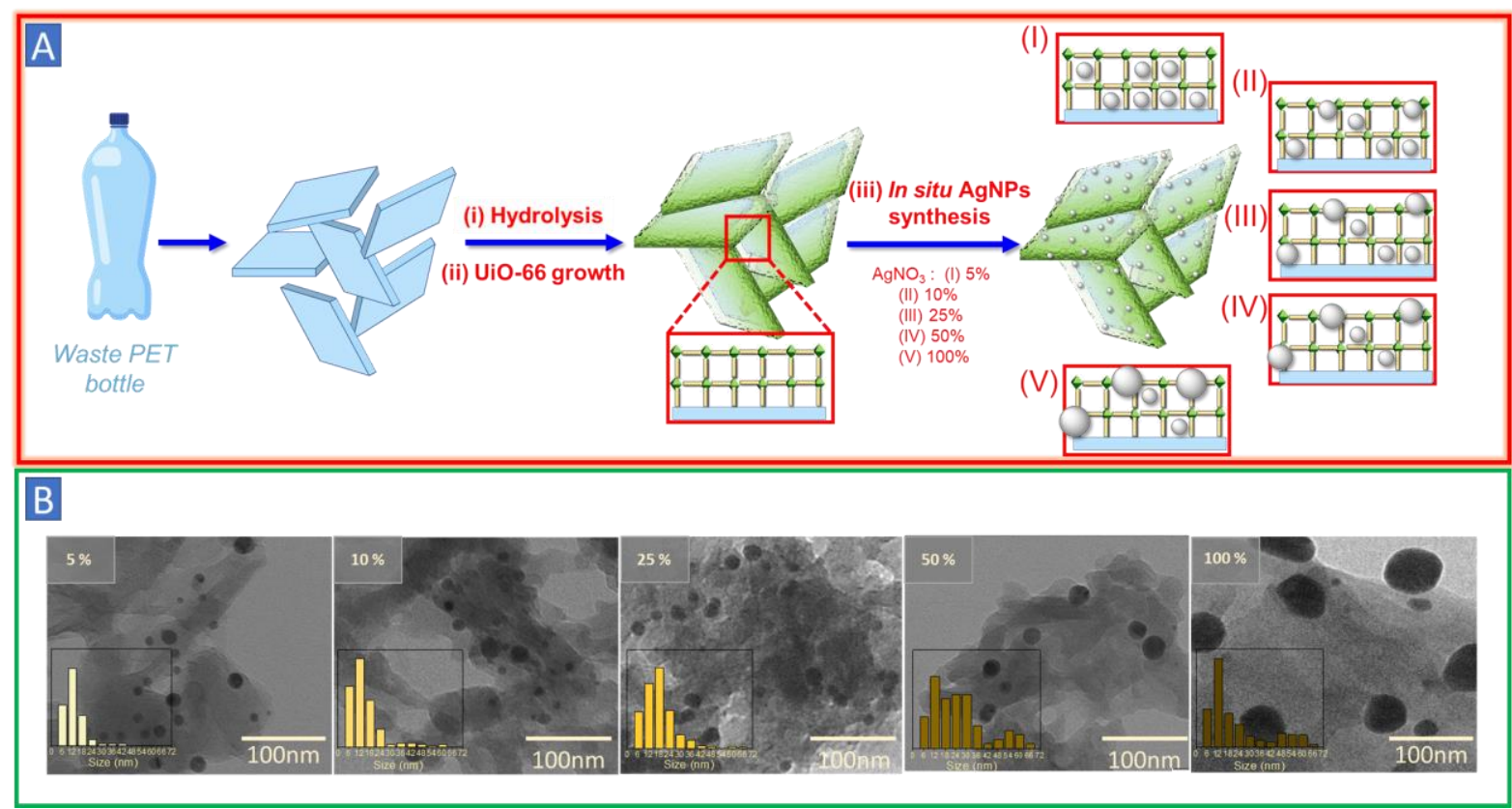

Figure 1. (A) - Scheme of UiO-66-Ag(5-100) preparation by (i) PET hydrolysis, (ii) UiO-66 growth, (iii) in situ AgNPs synthesis and five scenarios of AgNPs location, (B) - TEM images and AgNPs size distribution

\subsection{Preparation and optimization of PET@UiO-66-AgNPs}

For the deposition of AgNPs we used adopted an experimental procedure [20,21], where $0.1 \mathrm{~g}$ of PET@UiO-66 was premixed with different amounts of $\mathrm{AgNO}_{3}$ from 5 w. \% to $100 \mathrm{w}$. $\%$ in $\mathrm{CH}_{3} \mathrm{CN}$ for $14 \mathrm{~h}$ to homogeneously distributed $\mathrm{Ag}$ precursor into the pores. Further reduction of $\mathrm{AgNO}_{3}$ by $\mathrm{NaBH}_{4}(1: 1.7 \mathrm{~mol}$ ratio) led to the immediate color change of the suspension and formation of AgNPs. Resulting PET@UiO-66-Ag(5-100) were separated, washed and activated at vacuo in overnight.

The equal content of $\operatorname{Zr} 2.5 \pm 0.3 \%$ on PET@UiO-66-Ag(5-100) within all experiments demonstrated the high reproducibility of experimental procedures and stability of porous MOF layer suited for the further AgNPs deposition (Table 1). While $\mathrm{Zr}$ content was constant, Ag 
concentration was gradually raising up to $\sim 1 \%$ with the added $\mathrm{AgNO}_{3}$ increase (Table 1 ). The residual weights of PET@UiO-66-Ag(5-100) after TGA analysis (Fig. S3) with heating to 600 ${ }^{\circ} \mathrm{C}$ were consistent with ICP-MS data, the amount of residual $\mathrm{ZrO}_{2}$ and oxidized AgNPs was gradually increasing, confirming the successful deposition of AgNPs into PET@UiO-66AgNPs.

Table 1. Weight concentration of $\mathrm{Zr}$ and $\mathrm{Ag}$ according to ICP-MS and $\mathrm{ZrO}_{2}+\mathrm{Ag}_{\mathrm{x}} \mathrm{O}$ residuals after TG measurements

\begin{tabular}{|c|c|c|c|}
\hline \multirow{2}{*}{ Sample } & \multicolumn{2}{|c|}{ ICP-MS, \% } & TG, \% \\
\cline { 2 - 4 } & Zr & Ag & ZrO $_{2}+$ Ag $_{\mathbf{x}}$ O \\
\hline PET@UiO-66-Ag5 & $2.19 \pm 0.37$ & $0.43 \pm 0.09$ & 3.39 \\
\hline PET@UiO-66-Ag10 & $2.46 \pm 0.42$ & $0.37 \pm 0.07$ & 3.68 \\
\hline PET@UiO-66-Ag25 & $2.69 \pm 0.44$ & $0.61 \pm 0.10$ & 4.04 \\
\hline PET@UiO-66-Ag50 & $2.53 \pm 0.43$ & $0.73 \pm 0.15$ & 4.84 \\
\hline PET@UiO-66-Ag100 & $2.84 \pm 0.48$ & $0.92 \pm 0.18$ & 5.21 \\
\hline
\end{tabular}

\subsubsection{Microscopic methods (SEM, TEM)}

For the analysis of AgNPs size and distribution over PET@UiO-66, 5 types of materials were analyzed by transmission (TEM) and scanning electron microscopies (SEM). Pristine PET@UiO-66 has a porous morphology with highly-packed homogeneously distributed Zr over the chips (Fig. S1D, E). Further addition of 5 w.\% Ag followed by reduction with borohydride leads to the formation of AgNPs with two main fractions: $\sim 12.5 \mathrm{~nm}$ and $5 \mathrm{~nm}$ (Fig. 1B, S2). The coexistence of $5 \mathrm{~nm}$ AgNPs and larger AgNPs revealed that the porous surface structure of UiO-66 could partially provide steric restriction to prevent the growth during formation of Ag nanocrystals. An increase in Ag to 10 w.\% leads to the appearance of AgNPs fraction with larger size $>20 \mathrm{~nm}$. Addition of $25 \mathrm{mg} \mathrm{AgNO}_{3}$ leads to the formation of uniform 18.6 nm AgNPs homogeneously distributed over PET@UiO-66. Further increase leads to the formation of mainly 2 fractions sized by $\sim 12.8-30 \mathrm{~nm}$ and $55 \mathrm{~nm}$ with inhomogeneous distribution. SEM data confirmed the appearance of larger AgNPs fraction with the increase of $\mathrm{AgNO}_{3}$ amount (Fig. S2). So, chemical reduction of $\mathrm{AgNO}_{3}$ in the presence of PET@UiO-66 leads to the formation of round shaped AgNPs, where the size distribution 
depends on the precursor amount: the addition of a larger amount of Ag precursor leads to the appearance of a larger AgNPs fraction $55 \mathrm{~nm}$ coexisted with smaller AgNPs.

Based on previous reports, PNPs incorporation inside MOF lead to the three possible scenarios [22]: (a) nanoparticles are preferentially deposited at the external surface of the MOF crystal with particle size larger than the accessible pore dimension (Fig. 1A-V); (b) nanoparticles can be distributed throughout the bulk of the MOF, where they are still larger in size than the characteristic pore dimension (Fig. 1A-III); (c) well-dispersed metal nanoparticles (Fig. 1A-I). According to TEM and SEM, in our case, the increase of $\mathrm{AgNO}_{3}$ amount from 5 $\%$ to $100 \%$ lead to the smooth transition from (c) to the (b) scenario, where AgNPs are located inside and outside pores (Fig. 1B, S2).

\subsubsection{Plasmonic properties}

The deposition of AgNPs to PET@UiO-66 leads to significantly enhanced light absorbance in the visible region near 450 nm compared to pristine PET@UiO-66 (Fig. S1C). With increasing of AgNPs amount, we observed the relative growth of the absorbance peak from 1.2 to 1.4 (Fig. 2A). Depending on materials PET@UiO-66-Ag(5-100) with different AgNPs size distribution as in Fig. 2B, electric field (EF) in the direct vicinity of the AgNPs should be enhanced differently. We calculated the enhancement for each materials using Generalized Multiparticle Mie theory [23]. Local field enhancement was approximated as squared norm of the scattered field, since in the vicinity of NP surface scattered field is much greater than incoming field (unit amplitude is assumed). Taking into account the fact that intensity of Raman signal is proportional to the fourth power of field amplitude [24], the fourth power $\left(\left|E_{N P s} / E_{r e f}\right|^{4}\right)$ of resulting distribution was plotted in Fig. 2B. These $\left|E_{N P s} / E_{r e f}\right|^{4}$ distribution functions define probable ranges for EF enhancement, where there is a growth of enhancement from $5 \%$ to $50 \%$ Ag loading. The experimental data of Raman peaks intensities of methylene blue is consistent with calculation results, suggesting the highest field enhancement in case of PET@UiO-66-Ag50,100 (Fig. S4). 

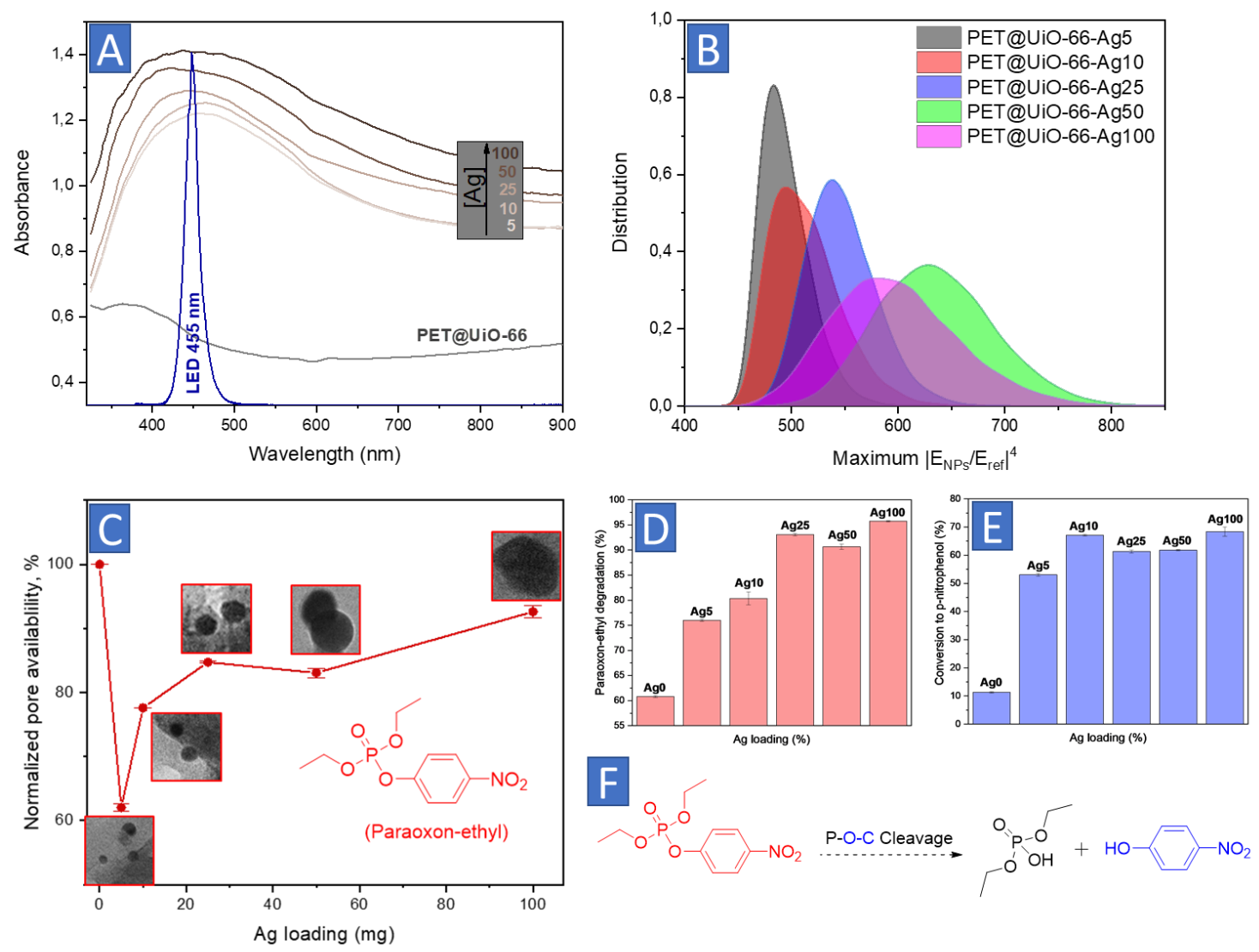

Figure 2. (A) - UV-Vis spectra measured from equal amounts of solid PET@UiO-66(Ag) and irradiance of 455 nm LED, (B) - Distribution of $\left|E_{N P s} / E_{r e f}\right|^{4}$ on AgNPs with size distribution corresponded to Fig. 1B, (C) - Pore availability in PET@UiO-66(Ag) and TEM images insert (size 60×60 nm²), (D), (E) - Paraoxon-ethyl degradation efficiency and conversion to p-nitrophenol in PET@UiO-66(Ag), (F) - scheme of paraoxon-ethyl degradation products

\subsubsection{Pore availability}

The location of AgNPs is equally important to plasmonic enhancement, where most of the reports suggest that scenario (a) is preferable for chemical transformations [25]. This is because NPs size is determined by the porosity, and resulting NPs usually are a few $\mathrm{nm}$ in diameter, leading to homogeneous NPs distribution and further plasmon excitation inducing chemical transformation. However, the efficiency of chemical transformation in porous materials, where pores are serving as nanoreactors, also depends on their availability [26,27]. This calls into question the optimal location (scenario a, b or c) of AgNPs for plasmonic degradation using MOF-PNPs composite. This is especially critical for plasmonic degradation of toxicants, where paraoxon-ethyl firstly has to penetrate into pores [28], chemosorbed via non-covalent interactions and coordinate to Lewis active site [29]. Therefore, we evaluated the possibility of PET@UiO-66-AgNPs to absorb paraoxon-ethyl in aqueous media, where pure 
PET@UiO-66 was considered as a starting material with $100 \%$ pore availability. Introduction of $5 \mathrm{w} . \% \mathrm{Ag}$ (scenario (a)+(b)) led to the sharp decrease of pore availability to $62 \%$, that can be explained by the large amount of small 5-10 nm AgNPs occupying the pore volume and precluding paraoxon-ethyl chemisorption to pores (Fig. 1B). The increase of the larger AgNPs fraction (scenario (b)+(c)) led to the recovery of pore availability in water to $85 \%$ (Fig. 2C). Therefore, we conclude that for the careful engineering of hybrid material PET@UiO-66AgNPs, we have to consider not only the plasmonic enhancement, size and amount of PNPs but also the availability of MOF-NPs pores for further effective paraoxon-ethyl penetration and interaction.

\subsubsection{Photocatalytic efficiency}

In quest of the balance between pore availability, plasmonic enhancement, and cost minimization, PET@UiO-66-Ag(5-100)were involved in the plasmon-induced degradation of $10 \mathrm{mg} / \mathrm{mL}$ paraoxon-ethyl using LED source of light with $455 \mathrm{~nm}$ wavelength, which is perfectly overlapping with the maximum of plasmon resonance of PET@UiO-66-Ag(5-100) (Fig. 2A). The degradation of paraoxon-ethyl using UiO-66 is commonly hydrolytically degrading through the cleavage of phosphonate ester bonds [29] with the formation of pnitrophenol and diethyl phosphate [30,31]. Therefore, for the evaluation of adsorption/degradation efficiency of PET@UiO-66-Ag(5-100), we used the concentrations of paraoxon-ethyl and p-nitrophenol measured by HPLC-UV using standard calibration curves (Fig. S6). Changes of concentrations were further recalculated to percentage of degradation efficiency and conversion of p-nitrophenol. For the evaluation of plasmonic contributions varied by different size and AgNPs content, we preliminary performed a scope of control experiments. Firstly, we evaluated the degradation efficiency of paraoxon-ethyl, which absorbs at $275 \mathrm{~nm}$ (Fig. S7B) at daylight, under $275 \mathrm{~nm}$ and under $455 \mathrm{~nm}$ after 1 hour of storage (daylight) or irradiation. There is almost no degradation of paraoxon-ethyl in the daylight, at 275 and $455 \mathrm{~nm}$ (<5\% efficiency). Therefore, any further degradation of paraoxon-ethyl has to be attributed to catalytic processes rather than for photolysis.

While pristine PET@UiO-66 is able to achieve $61 \% \times \mathrm{h}^{-1}$ paraoxon degradation efficiency, PET@UiO-66-Ag(5-100) under 455 nm LED was generally progressing from 76 $\% \times \mathrm{h}^{-1}$ to $95 \% \times \mathrm{h}^{-1}$ with the increase of Ag loading to $25 \%$. The deposition of $5 \mathrm{w} . \%$ of $\mathrm{Ag}$ leads to the negligible $3 \% \times \mathrm{h}^{-1}$ increase in efficiency (Fig. S7B), despite the strong plasmonic enhancement and absorption at $455 \mathrm{~nm}$ (Fig. 2D), espousing the idea of the critical role of pore availability. Deposition of 25 w.\% of $\mathrm{Ag}$ as additional reactive sites leads to the significant 
improvement approaching quantitative degradation of paraoxon-ethyl. The further increase from $50 \mathrm{w} . \%$ to $100 \mathrm{w} . \%$ of $\mathrm{Ag}$ content did not lead to the prominent improvement and reached plateau, so there is no need to spend a higher amount of Ag precursor. These results mean that the impossibility of paraoxon-ethyl to reach the pores occupied by small-sized AgNPs is blocking the plasmonic mechanism of degradation inside the pore, suggesting the chemisorption as limiting stage (Fig. 2C). The localization of AgNPs in both inside and outside pore provides better efficiency for synergetic degradation due to the availability of both reactive side UiO-66 as Lewis acid and AgNPs as plasmonic catalyst. Therefore, we suppose that loading of $25 \% \mathrm{Ag}$ leads to the formation of optimal material, which accelerates the degradation more than 3 times.

\subsection{Characterization of PET@UiO-66-Ag25}

PET@UiO-66-Ag25 was chosen as optimal for plasmonic degradation of paraoxonethyl due to the fastest degradation rate combined with a minimum amount of deposited AgNPs (Fig. 2, 3A), therefore comprehensive characterization of materials was performed. Firstly, XRay powder diffraction (XRD) revealed the appearance of typical UiO-66 related peaks at 7.3 and 8.5 $5^{\circ}$ on PET@UiO-66 after solvothermal growth [32]. Further incorporation of AgNPs mostly preserved MOF-related peaks and a new $\operatorname{Ag}(111)$ peak at $38.1^{\circ}$ confirms $\mathrm{AgNPs}$ formation (Fig. 3B, insert) [33]. Fourier-transform infrared spectroscopy (FTIR) spectra of PET@UiO-66-Ag25 contain characteristic signals of both PET at $1718 \mathrm{~cm}^{-1}$, UiO-66 - 1594 $\mathrm{cm}^{-1}$ and $1386 \mathrm{~cm}^{-1}$ are asymmetric and symmetric stretches of COO-Zr bonds [30] (Fig. 3C, S1A). Moreover, typical peaks of AgNPs, prepared by chemical reduction, at $\approx 1500 \mathrm{~cm}^{-1}$ and $1650 \mathrm{~cm}^{-1}$ also appear [34]. X-ray photoelectron spectroscopy (XPS) demonstrates the appearance of $3.1 \%$ of $\mathrm{Zr}$ after in situ growth of UiO-66 (Tab. S1), where Zr 3d doublet perfectly correlated with the UiO-66 doublet $\mathrm{Zr} 3 \mathrm{~d}_{5 / 2} 182.6 \mathrm{eV}, \mathrm{Zr} 3 \mathrm{~d}_{3 / 2} 184.8 \mathrm{eV}$. After the integration of AgNPs from the survey spectra, we can see the appearance of $1.33 \%$ of Ag (Fig. 3D, Tab. S1). The $3 \mathrm{~d}_{5 / 2}$ and $3 \mathrm{~d}_{3 / 2}$ peak positions of PET@UiO-66 and presence of loss feature peaks correspond to metallic silver atoms without the oxide phase (Fig. 3E) [35]. 

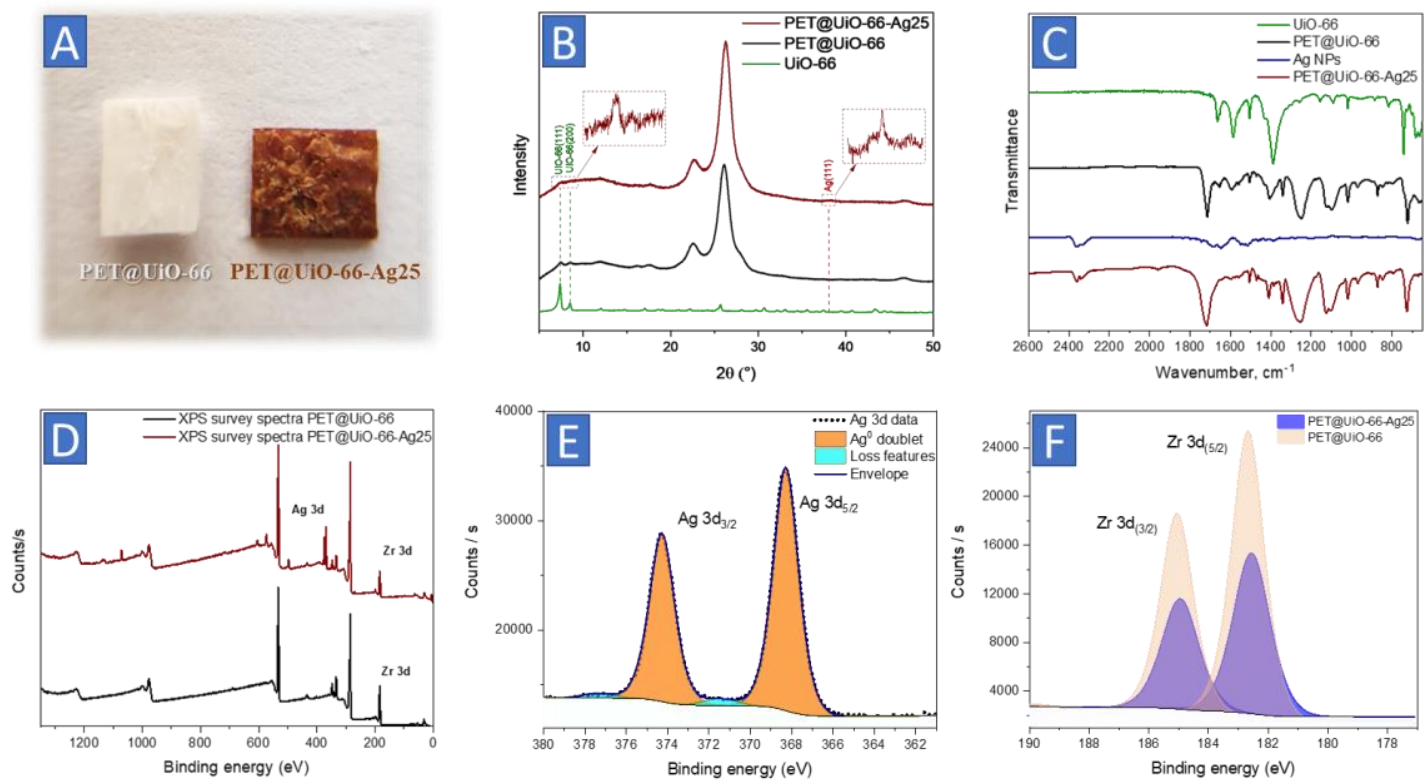

Figure 3. Characterization of AgNPs, UiO-66, PET@UiO-66 and PET@UiO-66-Ag25: (A) - Photos of PET@UiO-66 and PET@UiO-66Ag25 (B) - XRD pattern (C) - FTIR spectra (D) - XPS survey spectra of PET@UiO-66 and PET@UiO-66-Ag25 (E) - XPS spectra of Ag 3d region of PET@UiO-66-Ag25 (F) - XPS spectra of Zr 3d region of PET@UiO-66 and PET@UiO-66-Ag25

\subsection{Kinetic of synergetic degradation}

We investigated the kinetic of synergetic paraoxon-ethyl degradation using optimal PET@UiO-66-Ag25 as a function of illumination time from 0 min to 180 min using $455 \mathrm{~nm}$ LED (Fig 4A, B). The illumination of paraoxon-ethyl without any PET-based materials leads to the $\sim 5 \% \times \mathrm{h}^{-1}$ degradation comparable with the daylight (Fig. S7B). When PET-hydrolyzed and PET@UiO-66 come into play, there is a dramatic decrease of paraoxon-ethyl concentration occurring in the first 5 minutes after their contact, confirming the pore availability for chemisorption of paraoxon-ethyl. 

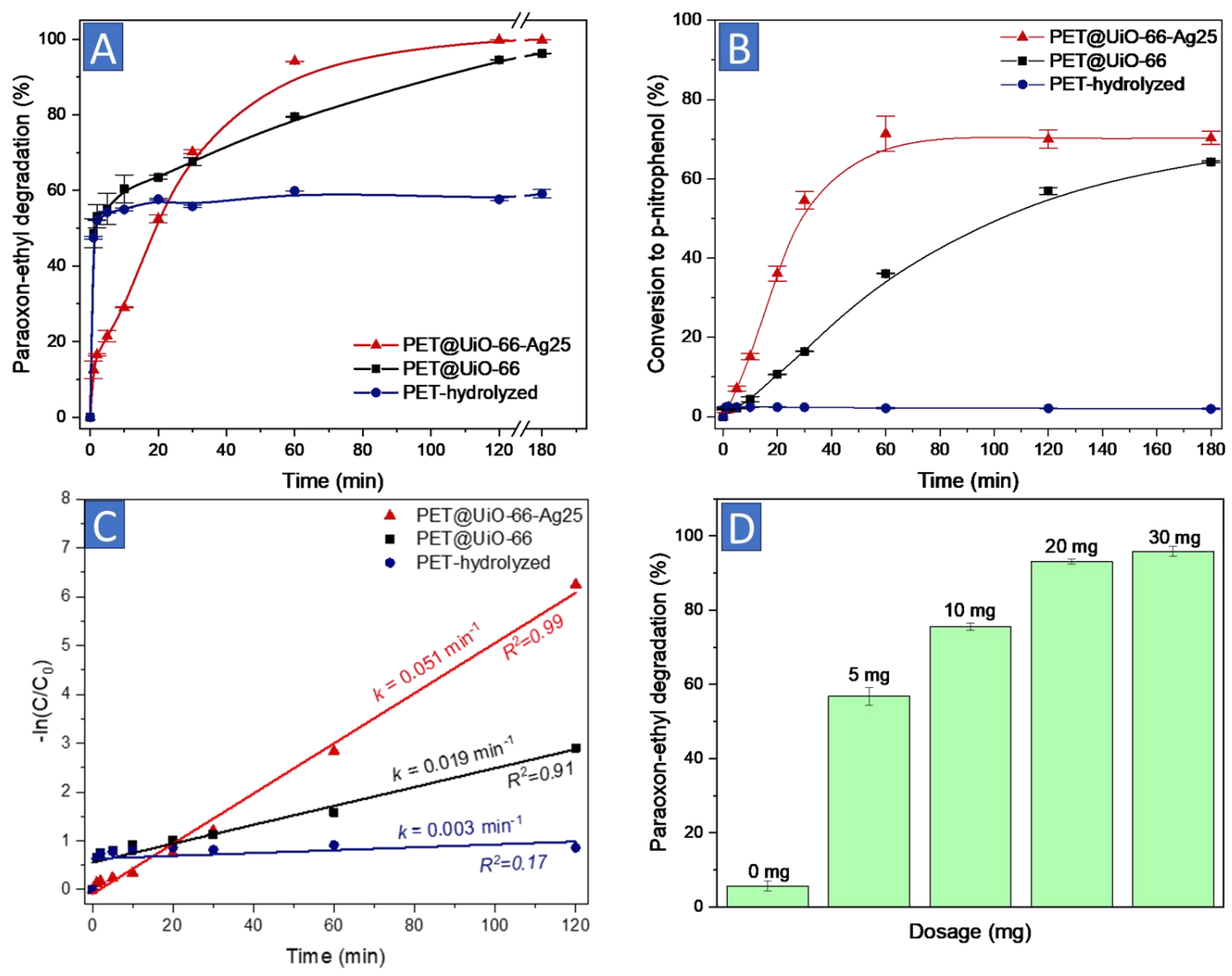

Figure 4 (A) - Effect of contact time on the degradation of paraoxon-ethyl with hydrolyzed PET chips, PET@UiO-66 and PET@UiO-66Ag25 using $455 \mathrm{~nm}$ LED (B) - Effect of contact time on the conversion of paraoxon-ethyl to p-nitrophenol (C) - pseudo-first-order kinetic model (D) - Degradation of paraoxon-ethyl with different loading of PET@UiO-66-Ag25

While hydrolyzed PET is able only to absorb paraoxon-ethyl without any degradation due to the absence of catalytic centers (Fig. 4A,B), PET@UiO-66 displays moderate degradation activity. For the quantitative evaluation of the degradation activity, a pseudo-first kinetic model has been suggested as suitable for both heterogeneous processes: plasmonic degradation and UiO-66-driven hydrolysis. Therefore, the obtained kinetic data were fitted according to the equation (1):

$$
\ln \left(C_{t} / C_{0}\right)=-k t
$$

where $C_{t}(\mathrm{mg} / \mathrm{L})$ - is the concentration of the solution at time $t ; C_{0}(\mathrm{mg} / \mathrm{L})$ - is the initial concentration of the paraoxon-ethyl solution, $t(\mathrm{~min})$ - is the time of adsorption, $k$ - is the firstorder rate constant. 
The perfect fitting to the pseudo-first kinetic model with $\mathrm{R}^{2}=0.99$ allows to calculate degradation rate constants as a slope of the linear plot (Fig. 4C). While PET@UiO-66 shows $0.019 \mathrm{~min}^{-1}$ constant rate, the deposition of AgNPs accelerates paraoxon-ethyl degradation more than 3 times. So, PET@UiO-66-Ag25 was extremely effective for the synergetic degradation of paraoxon-ethyl - just 1 hour for the $95 \%$ degradation. The amount of released p-nitrophenol to the solution is slightly less than degraded paraoxon-ethyl because of retention in $\mathrm{UiO}-66$ pores or further decomposition to small molecules.

\subsection{Amount of PET@UiO-66-Ag25 and stability}

The optimized amount of catalyst plays a key role in the effective degradation of paraoxon-ethyl and avoiding catalyst wastage. Therefore, we investigated the influence of a different amount of catalyst from $0 \mathrm{mg}$ to $30 \mathrm{mg}$ on the plasmonic degradation of paraoxonethyl (Fig. 4D). Without PET@UiO-66-Ag25 almost no degradation was observed, while the addition of $5 \mathrm{mg}$ leads to the $57 \% \times \mathrm{h}^{-1}$ efficiency. A further increase to $20 \mathrm{mg}$ led to almost $100 \% \times \mathrm{h}^{-1}$ degradation of paraoxon-ethyl, where enlarged amount of catalyst did not affect the degradation rate due to the attainment of equilibrium. Therefore 20 mg of PET@UiO-66-Ag25 is the optimal amount for effective degradation. One more crucial parameter for practical applications is environmental stability and the possibility of multiple utilization. The testing of PET@UiO-66-Ag25 in a few cycles of washing/degradation demonstrated the perfect stability after 3 cycles without the synergetic degradation activity loss $\left(95 \% \times \mathrm{h}^{-1}\right)($ Fig. 5A). After 4 th and 5th cycles there is a slight reduction efficiency due to the possible partial oxidation revealed by the shift of Ag 3d peaks in XPS spectra (Fig. 5B). 

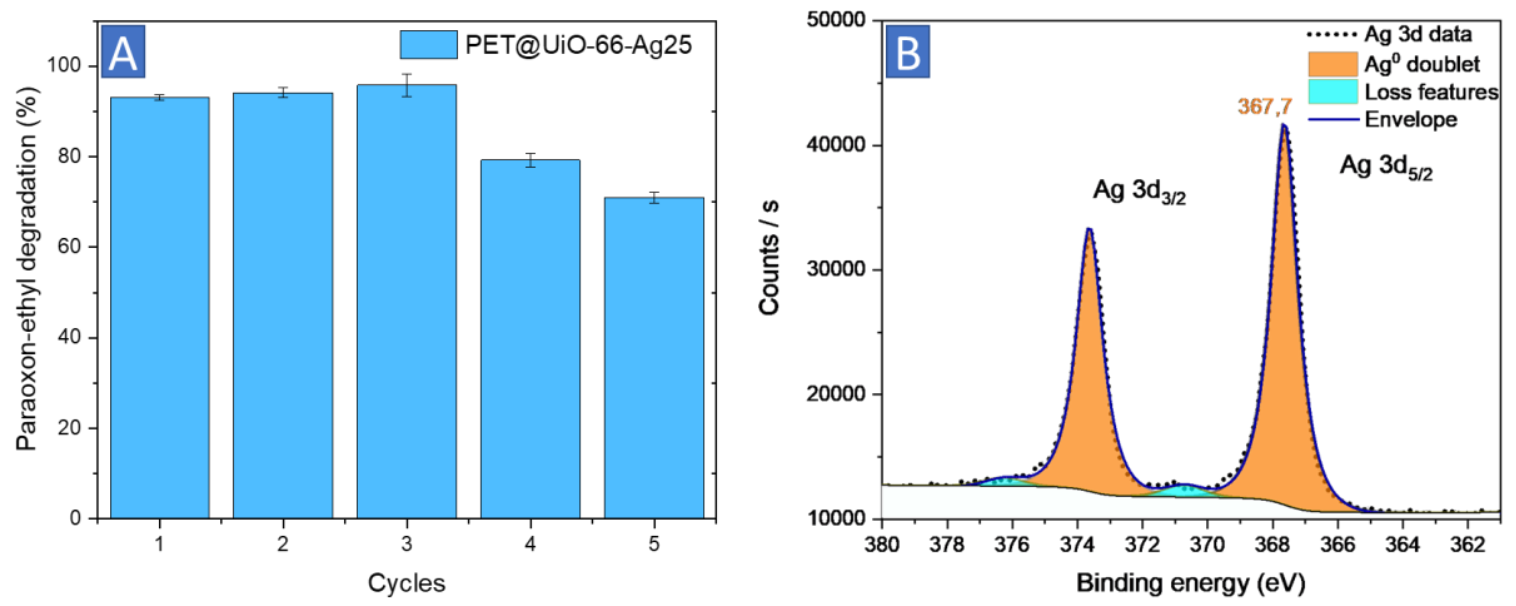

Figure 5. (A) - Effect of numbers of cycles on the degradation paraoxon-ethyl (B) - XPS of Ag 3d region of PET@UiO-66-Ag25 after $5^{\text {th }}$ cycle

\subsection{Comparison with other materials}

As was mentioned above, UiO-66 and other Zr-containing MOF are able to hydrolyze paraoxon-ethyl [29]; however, the $\mathrm{pH}$ increase is required via buffer addition to accelerating the degradation rate, making the procedure less environmentally friendly [36,37] (Table 2). Moreover, the recycling possibility has not been reported. $\mathrm{TiO}_{2}$-based materials are more active, but suffer from the low surface area [38,39] and possible agglomeration leading to moderate recycling ability [38]. The last generation of semiconducting materials is one of the most promising [13,40], however, suggested here PET@UiO-66-Ag25 is overperforming them in terms of easiness of preparation, time to quantitative degradation, visible light usage and recycling performance (Table 2). 
Table 2. Overview of hybrid materials for paraoxon-ethyl degradation

\begin{tabular}{|c|c|c|c|c|c|}
\hline Materials & Preparation methods & $\begin{array}{c}\text { Time to } \\
\text { quantitative } \\
\text { degradation }^{\mathrm{a}}\end{array}$ & $\begin{array}{c}\text { Light } \\
\text { wavelength, } \\
\mathbf{n m}\end{array}$ & Recyclability & Ref \\
\hline $\begin{array}{l}\text { UiO-66, UiO-67, NU- } \\
1000, \text { PCN-222 }{ }^{\text {b }}\end{array}$ & Solvothermal synthesis & 120 & - & - & [36] \\
\hline $\begin{array}{l}\text { PMMA/PVDF/Ti(OH) } \\
@_{\mathrm{TiO}_{2} @ U \mathrm{UiO}-66^{\mathrm{b}}}\end{array}$ & $\begin{array}{l}\text { sol-gel synthesis and } \\
\text { electrospinning, ALD, } \\
\text { solvothermal synthesis }\end{array}$ & $>120 \mathrm{~min}$ & - & - & [37] \\
\hline $\mathrm{Ag} @ \mathrm{TiO}_{2}$ & Chemical reduction & $1440 \mathrm{~min}$ & 400 & $\begin{array}{c}2 \text { cycles w/o } \\
\text { loss }\end{array}$ & [38] \\
\hline $\begin{array}{l}\text { Anisotropic AgNPs on } \\
\mathrm{TiO}_{2} \text { fibers }\end{array}$ & $\begin{array}{l}\text { sol-gel synthesis, } \\
\text { electrospinning, thermal } \\
\text { treatment }\end{array}$ & $>120 \mathrm{~min}$ & 640 & - & [39] \\
\hline $\begin{array}{l}\text { La-doped } \mathrm{ZnO} \text { nanorods } \\
\text { containing PAN } \\
\text { nanofiber }\end{array}$ & $\begin{array}{c}\text { Electrospinning, } \\
\text { hydrothermal synthesis }\end{array}$ & $150 \mathrm{~min}$ & 365 & - & [13] \\
\hline $\begin{array}{l}\mathrm{NbOFe} \text {-nanofiber based } \\
\text { on polycaprolactone }\end{array}$ & $\begin{array}{c}\text { Electrospinning, } \\
\text { hydrothermal synthesis }\end{array}$ & $>2000 \mathrm{~min}$ & $\begin{array}{c}500-800 \\
\text { (white light) }\end{array}$ & - & [40] \\
\hline PET@UiO-66Ag25 & $\begin{array}{l}\text { Solvothermal synthesis } \\
\text { from polymer waste, } \\
\text { chemical reduction }\end{array}$ & $60 \mathrm{~min}$ & 455 & $\begin{array}{c}3 \text { cycles w/o } \\
\text { loss }\end{array}$ & This work \\
\hline
\end{tabular}

a -degradation to $95-100 \%$

b - N-ethyl morpholine or PBS buffer was used as media, $\mathrm{pH}$ 9-10 


\subsection{Plausible pathways of synergetic degradation using PET@UiO-66-Ag25}

The observed degradation efficiency is the consequence of the synergetic action of PET@UiO-66 and deposited AgNPs (Fig. 6). As we proved above, the penetration of paraoxon-ethyl into UiO-66 pores is one of the critical steps (Fig. 2C), where paraoxon-ethyl further coordinates to Lewis acidic active site. Further, there is a nucleophilic attack of the hydroxyl on the organophosphorus substrate with the elimination of the leaving group from the organophosphorus substrate leading to ester bonds cleavage [29] (Fig. 6, Pathway I). The PETUiO-66 is degrading paraoxon to $61 \% \times \mathrm{h}^{-1}$. (Fig. 7A).

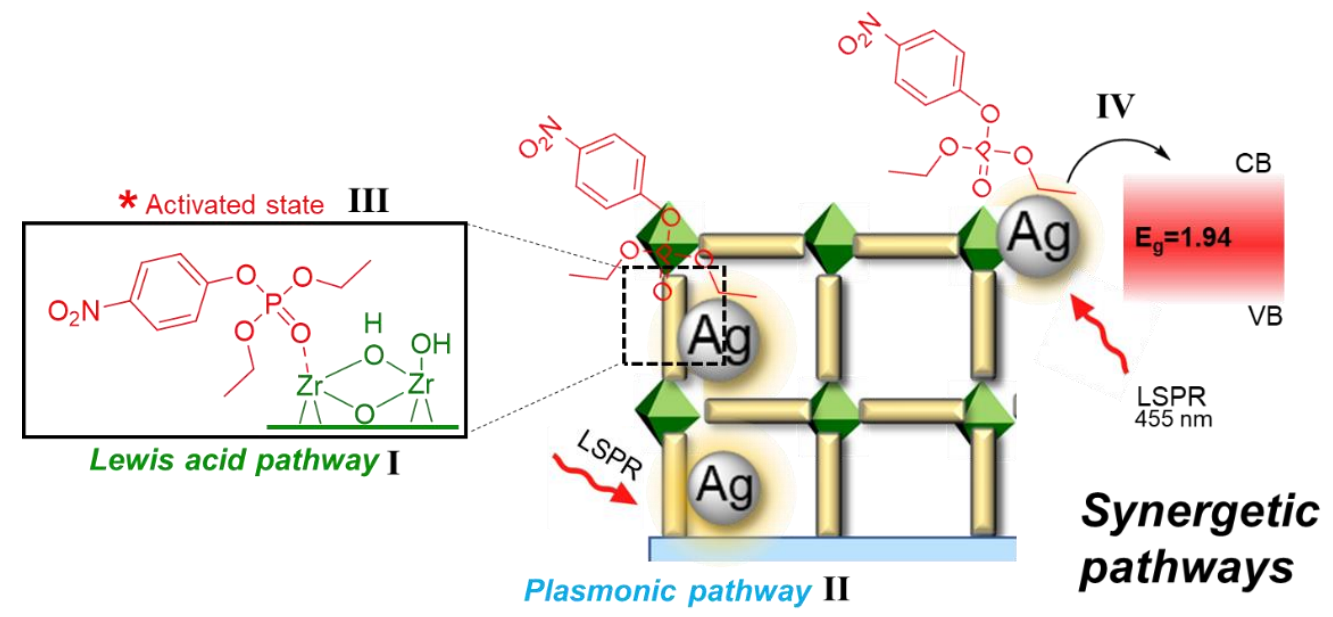

Figure 6. Plausible mechanistic pathways for synergetic degradation of paraoxon-ethyl using PET@UiO-66-Ag25

Deposition of AgNPs advantages from the high optical absorption in the visible region the availability of a large number of high-energy states at their surface to initiate the chemical reaction with adsorbed molecules under $455 \mathrm{~nm}$ LED illumination (Fig. 6, Pathway II). We tested the degradation of paraoxon-ethyl using AgNPs $(\approx 20 \mathrm{~nm})[41]$, prepared by the chemical reduction method [42] (Fig. S7B, C and related discussion). The equal amount of AgNPs (0.12 $\mathrm{mg}$ ) provide only $28 \% \times \mathrm{h}^{-1}$ degradation of paraoxon-ethyl (Fig. 7A) [43].

Additional pathways appear due to the energy transfer between PET@UiO-66 and AgNPs. Zr sites are forming transition states with paraoxon-ethyl for nucleophilic attack. In that case, light absorption on AgNPs and further plasmon excitation lead to the energy transfer to transition state for activation via the weakening the chemical bonds in the reactant molecule, enhancing the Lewis acidity of metal centers [44,45] (Fig. 6, pathway III). Moreover, because of the incorporation of AgNPs into UiO-66, $E_{g}$ is reduced from $2.49 \mathrm{eV}$ to $1.94 \mathrm{eV}$ (Fig. S5); therefore, $455 \mathrm{~nm}$ light $(2.7 \mathrm{eV})$ is enough to excite conduction band (CB) in PET@UiO-66- 
Ag25 and additionally excite transition state with Zr (Fig. 6, pathway IV). Combination of Lewis acid activity, plasmonic effects and their combination led to the $>95 \%$ degradation of paraoxon-ethyl using PET@UiO-66-Ag25 using visible light exceeding each of pathway.

Deposition of AgNPs provides synergetic pathways for the degradation of paraoxonethyl overperforming the Lewis acid and plasmonic pathways (Fig. 7A). The synergetic effect of AgNPs deposition has been tested via the variation of wavelength excitation (Fig. 7B). Using $275 \mathrm{~nm}(4.5 \mathrm{eV})$ wavelength leads to low degradation efficiency despite the strong adsorption at $\approx 300 \mathrm{~nm}$ due to PET@UiO-66 (Fig. S1C). The shift of LED light to longer $455 \mathrm{~nm}$ wavelengths facilitate more effective plasmon excitation and transfers to Lewis acids sites. At the same time, the further increase of LED wavelength to $630 \mathrm{~nm}$ and $780 \mathrm{~nm}$ leads to slight quenching of degradation efficiency. Simultaneously with degradation efficiency, we calculated apparent quantum yield (AQY) as the ratio of the degraded paraoxon-ethyl in moles per moles of absorbed photons. AQY at optimal conditional is reaching $1 \%$, which is comparable or improved compared to, for example, $\mathrm{Ag} / \mathrm{TiO}_{2}$ photocatalytic degradation of volatile organic compounds [46]. There is a clear dependence of degradation efficiency and AQY with the absorbance spectra of PET@UiO-66 confirming the significant plasmonic contribution in all pathways, enhancing the Lewis acid centers for efficient degradation (Fig. 7B).
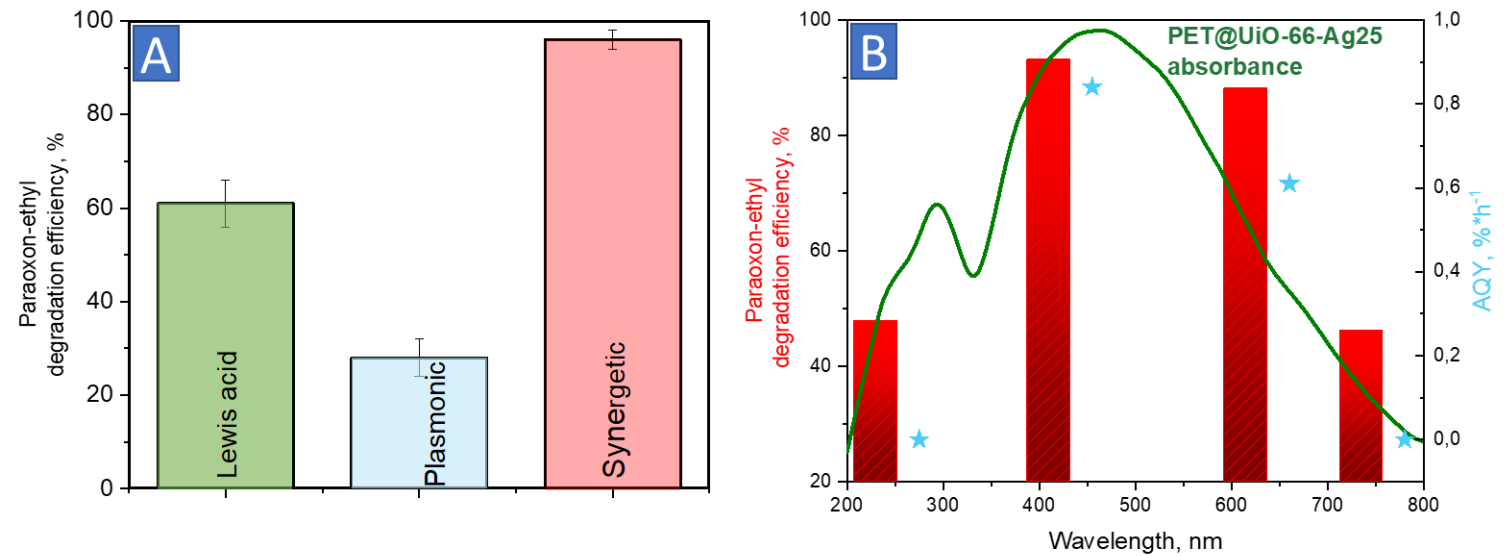

Figure 7. (A) - paraoxon-ethyl degradation efficiency degradation by Lewis acid, plasmonic and synergetic pathways (B) - Dependence of paraoxon-ethyl degradation efficiency on the illumination wavelength 


\section{Conclusion}

Here, we prepared a novel hybrid plasmonic material starting from waste PET for the effective degradation of paraoxon ethyl in aqueous media using visible light. The controlled deposition of plasmonic AgNPs to PET@UiO-66 results in the new photoactive materials, where MOF exhibiting Lewis acid activity is enhanced AgNPs. In quest of the balance between pore availability for paraoxon-ethyl adsorption to Lewis sites, plasmonic enhancement, and cost minimization, we found an optimal material PET@UiO-66-Ag25, where AgNPs are located both inside and outside MOF's pores to make MOF pores available for paraoxon-ethyl adsorption. The prepared material was characterized by a number of spectroscopic XRD, UVVis, FTIR, XPS), and microscopic (SEM, TEM) techniques. PET@UiO-66-Ag25 is overperforming MOFs and semiconductor-based materials in terms of environmental impact (waste PET as starting materials), easiness of preparation, short time to quantitative degradation ( $1 \mathrm{~h}$ to $>95 \%$ ), visible light usage $(455 \mathrm{~nm})$, and recycling performance (up to 5 cycles). This outstanding performance can be explained by the synergetic pathways for the degradation of paraoxon-ethyl overperforming, where Lewis's acid activity is enhanced by the additional plasmon excitation.

\section{Declaration of Competing Interest}

The authors declare that they have no known competing financial interests or personal relationships that could have appeared to influence the work reported in this paper.

\section{Funding}

The research has been supported by RFBR 19-33-90212 (the design, preparation and characterization of composite material) and RSF 20-73-0015 (evaluation of plasmonic properties and catalytic activity).

\section{Acknowledgement}

The authors thank the central laboratories of TPU (Analytical Center) for the XPS measurements and Tomsk Regional Core Shared Research Facilities Centre of National Research Tomsk State University for the TGA, ICP-MS, SEM and TEM measurements.

\section{Appendix A. Supplementary data}




\section{References}

[1] F.P. Carvalho, Pesticides, environment, and food safety, Food Energy Secur. 6 (2017) 48-60. https://doi.org/10.1002/FES3.108.

[2] S. Pang, T. Yang, L. He, Review of surface enhanced Raman spectroscopic (SERS) detection of synthetic chemical pesticides, TrAC Trends Anal. Chem. 85 (2016) 73-82. https://doi.org/10.1016/J.TRAC.2016.06.017.

[3] E. Malaj, P.C. von der Ohe, M. Grote, R. Kühne, C.P. Mondy, P. Usseglio-Polatera, W. Brack, R.B. Schäfer, Organic chemicals jeopardize the health of freshwater ecosystems on the continental scale, Proc. Natl. Acad. Sci. 111 (2014) 9549-9554. https://doi.org/10.1073/PNAS.1321082111.

[4] Wang Xin, Yonghui Song, Mesoporous carbons: recent advances in synthesis and typical applications, RSC Adv. 5 (2015) 83239-83285. https://doi.org/10.1039/C5RA16864C.

[5] S.I. Rathnayake, Y. Xi, R.L. Frost, G.A. Ayoko, Environmental applications of inorganic-organic clays for recalcitrant organic pollutants removal: Bisphenol A, J. Colloid Interface Sci. 470 (2016) 183-195. https://doi.org/10.1016/J.JCIS.2016.02.034.

[6] Y. Cao, L. Huang, Y. Bai, K. Jermsittiparsert, R. Hosseinzadeh, H. Rasoulnezhad, G. Hosseinzadeh, Synergic effect of oxygen vacancy defect and shape on the photocatalytic performance of nanostructured TiO2 coating, Polyhedron. 175 (2020) 114214. https://doi.org/10.1016/J.POLY.2019.114214.

[7] A. Sellik, T. Pollet, L. Ouvry, S. Briançon, H. Fessi, D.J. Hartmann, F.N.R. Renaud, Degradation of paraoxon (VX chemical agent simulant) and bacteria by magnesium oxide depends on the crystalline structure of magnesium oxide, Chem. Biol. Interact. 267 (2017) 67-73. https://doi.org/10.1016/J.CBI.2016.11.023.

[8] L.E. Lange, S. Kay Obendorf, Degradation studies of methyl parathion with CuBTC metal-organic framework, J. Environ. Chem. Eng. 3 (2015) 541-547. https://doi.org/10.1016/J.JECE.2015.01.007.

[9] A.R. Bagheri, N. Aramesh, M. Bilal, New frontiers and prospects of metal-organic frameworks for removal, determination, and sensing of pesticides, Environ. Res. 194 (2021) 110654. https://doi.org/10.1016/J.ENVRES.2020.110654.

[10] K.-J. Wu, C. Wu, M. Fang, B. Ding, P.-P. Liu, M.-X. Zhou, Z.-Y. Gong, D.-L. Ma, C.H. Leung, Application of metal-organic framework for the adsorption and detection of food contamination, TrAC Trends Anal. Chem. $143 \quad$ (2021) 116384. https://doi.org/10.1016/J.TRAC.2021.116384.

[11] O. Semyonov, S. Chaemchuen, A. Ivanov, F. Verpoort, Z. Kolska, M. Syrtanov, V. Svorcik, M.S. Yusubov, O. Lyutakov, O. Guselnikova, P.S. Postnikov, Smart recycling of PET to sorbents for insecticides through in situ MOF growth, Appl. Mater. Today. 22 (2021) 100910. https://doi.org/10.1016/J.APMT.2020.100910.

[12] A.P. Bhat, P.R. Gogate, Degradation of nitrogen-containing hazardous compounds 
using advanced oxidation processes: A review on aliphatic and aromatic amines, dyes, $\begin{array}{llllll}\text { and pesticides, J. Hazard. Mater. } 403 \quad \text { (2021) } & 123657 .\end{array}$ https://doi.org/10.1016/J.JHAZMAT.2020.123657.

[13] K. Lakshmi, K. Kadirvelu, P.S. Mohan, Reclaimable La: ZnO/PAN nanofiber catalyst for photodegradation of methyl paraoxon and its toxicological evaluation utilizing early life stages of zebra fish (Danio rerio), Chem. Eng. J. 357 (2019) 724-736. https://doi.org/10.1016/J.CEJ.2018.09.201.

[14] X. Zhang, J. Wang, X.X. Dong, Y.K. Lv, Functionalized metal-organic frameworks for photocatalytic degradation of organic pollutants in environment, Chemosphere. 242 (2020) 125144. https://doi.org/10.1016/J.CHEMOSPHERE.2019.125144.

[15] X. Hu, X. Hu, Q. Peng, L. Zhou, X. Tan, L. Jiang, C. Tang, H. Wang, S. Liu, Y. Wang, Z. Ning, Mechanisms underlying the photocatalytic degradation pathway of ciprofloxacin with heterogeneous TiO2, Chem. Eng. J. 380 (2020) 122366. https://doi.org/10.1016/J.CEJ.2019.122366.

[16] M. Potara, M. Focsan, A.M. Craciun, I. Botiz, S. Astilean, Polymer-coated plasmonic nanoparticles for environmental remediation: Synthesis, functionalization, and properties, New Polym. Nanocomposites Environ. Remediat. (2018) 361-387. https://doi.org/10.1016/B978-0-12-811033-1.00015-9.

[17] A. Haghighi, M. Haghighi, M. Shabani, S.G. Fard, Oxygen-rich bismuth oxybromide nanosheets coupled with $\mathrm{Ag} 2 \mathrm{O}$ as Z-scheme nano-heterostructured plasmonic photocatalyst: Solar light-activated photodegradation of dye pollutants, J. Hazard. Mater. 408 (2021) 124406. https://doi.org/10.1016/J.JHAZMAT.2020.124406.

[18] O. Guselnikova, P. Postnikov, R. Elashnikov, E. Miliutina, V. Svorcik, O. Lyutakov, Metal-organic framework (MOF-5) coated SERS active gold gratings: A platform for the selective detection of organic contaminants in soil, Anal. Chim. Acta. 1068 (2019) 70-79. https://doi.org/10.1016/j.aca.2019.03.058.

[19] E. Miliutina, O. Guselnikova, V. Burtsev, R. Elashnikov, P. Postnikov, V. Svorcik, O. Lyutakov, Plasmon-active optical fiber functionalized by metal organic framework for

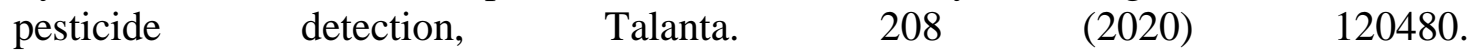
https://doi.org/10.1016/J.TALANTA.2019.120480.

[20] G. Dutta, A.K. Jana, D.K. Singh, M. Eswaramoorthy, S. Natarajan, Encapsulation of Silver Nanoparticles in an Amine-Functionalized Porphyrin Metal-Organic Framework and Its Use as a Heterogeneous Catalyst for $\mathrm{CO} 2$ Fixation under Atmospheric Pressure, Chem. - An Asian J. 13 (2018) 2677-2684. https://doi.org/10.1002/ASIA.201800815.

[21] S. Shakya, Y. He, X. Ren, T. Guo, A. Maharjan, T. Luo, T. Wang, R. Dhakhwa, B. Regmi, H. Li, R. Gref, J. Zhang, Ultrafine Silver Nanoparticles Embedded in Cyclodextrin Metal-Organic Frameworks with GRGDS Functionalization to Promote Antibacterial and Wound Healing Application, Small. 15 (2019) 1901065. https://doi.org/10.1002/SMLL.201901065.

[22] Y. Zhang, Y. Zhou, Y. Zhao, C.J. Liu, Recent progresses in the size and structure control of MOF supported noble metal catalysts, Catal. Today. 263 (2016) 61-68. 
https://doi.org/10.1016/J.CATTOD.2015.10.022.

[23] A. Ciesielski, L. Skowronski, M. Trzcinski, E. Górecka, P. Trautman, T. Szoplik, Evidence of germanium segregation in gold thin films, Surf. Sci. 674 (2018) 73-78. https://doi.org/10.1016/J.SUSC.2018.03.020.

[24] E.C. Le Ru, P.G. Etchegoin, Rigorous justification of the $|E| 4$ enhancement factor in Surface Enhanced Raman Spectroscopy, Chem. Phys. Lett. 423 (2006) 63-66. https://doi.org/10.1016/J.CPLETT.2006.03.042.

[25] M. Wang, Y. Tang, Y. Jin, Modulating Catalytic Performance of Metal-Organic Framework Composites by Localized Surface Plasmon Resonance, ACS Catal. 9 (2019) 11502-11514. https://doi.org/10.1021/ACSCATAL.9B03971.

[26] W.-Y. Gao, A.D. Cardenal, C.-H. Wang, D.C. Powers, In Operando Analysis of Diffusion in Porous Metal-Organic Framework Catalysts, Chem. - A Eur. J. 25 (2019) 3465-3476. https://doi.org/10.1002/CHEM.201804490.

[27] P. Canepa, N. Nijem, Y.J. Chabal, T. Thonhauser, Diffusion of small molecules in metal organic framework materials, Phys. Rev. Lett. $110 \quad$ (2013) 026102. https://doi.org/10.1103/PhysRevLett.110.026102.

[28] G.W. Peterson, S.-Y. Moon, G.W. Wagner, M.G. Hall, J.B. DeCoste, J.T. Hupp, O.K. Farha, Tailoring the Pore Size and Functionality of UiO-Type Metal-Organic Frameworks for Optimal Nerve Agent Destruction, Inorg. Chem. 54 (2015) 9684-9686. https://doi.org/10.1021/ACS.INORGCHEM.5B01867.

[29] K. Ma, M.C. Wasson, X. Wang, X. Zhang, K.B. Idrees, Z. Chen, Y. Wu, S.-J. Lee, R. Cao, Y. Chen, L. Yang, F.A. Son, T. Islamoglu, G.W. Peterson, J.J. Mahle, O.K. Farha, Near-instantaneous catalytic hydrolysis of organophosphorus nerve agents with zirconium-based MOF/hydrogel composites, Chem Catal. (2021). https://doi.org/10.1016/J.CHECAT.2021.06.008.

[30] J.Y. Seo, K.Y. Cho, J.-H. Lee, M.W. Lee, K.-Y. Baek, Continuous Flow Composite Membrane Catalysts for Efficient Decomposition of Chemical Warfare Agent Simulants, ACS Appl. Mater. Interfaces. 12 (2020) 32778-32787. https://doi.org/10.1021/ACSAMI.0C08276.

[31] Merck | Russian Federation, (n.d.). https://www.sigmaaldrich.com/RU/en (accessed August 4, 2021).

[32] F. Ahmadijokani, R. Mohammadkhani, S. Ahmadipouya, A. Shokrgozar, M. Rezakazemi, H. Molavi, T.M. Aminabhavi, M. Arjmand, Superior chemical stability of UiO-66 metal-organic frameworks (MOFs) for selective dye adsorption, Chem. Eng. J. 399 (2020) 125346. https://doi.org/10.1016/J.CEJ.2020.125346.

[33] R. Rajkumar, G. Ezhumalai, M. Gnanadesigan, A green approach for the synthesis of silver nanoparticles by Chlorella vulgaris and its application in photocatalytic dye degradation activity, Environ. Technol. Innov. $21 \quad$ (2021) 101282. https://doi.org/10.1016/J.ETI.2020.101282.

[34] Jianfeng Mao, Qinfen Gu, Zaiping Guo, H. Kun Liu, Sodium borohydride hydrazinates: 
synthesis, crystal structures, and thermal decomposition behavior, J. Mater. Chem. A. 3 (2015) 11269-11276. https://doi.org/10.1039/C5TA02276B.

[35] P. Prieto, V. Nistor, K. Nouneh, M. Oyama, M. Abd-Lefdil, R. Díaz, XPS study of silver, nickel and bimetallic silver-nickel nanoparticles prepared by seed-mediated growth, $\begin{array}{lllll}\text { Appl. } & \text { Surf. } & \text { Sci. } & 258 & \text { (2012) }\end{array}$ https://doi.org/10.1016/J.APSUSC.2012.05.095.

[36] A.M. Ploskonka, J.B. DeCoste, Insight into organophosphate chemical warfare agent simulant hydrolysis in metal-organic frameworks, J. Hazard. Mater. 375 (2019) 191197. https://doi.org/10.1016/J.JHAZMAT.2019.04.044.

[37] D.B. Dwyer, D.T. Lee, S. Boyer, W.E. Bernier, G.N. Parsons, J. Wayne E. Jones, Toxic Organophosphate Hydrolysis Using Nanofiber-Templated UiO-66-NH2 Metal-Organic Framework Polycrystalline Cylinders, ACS Appl. Mater. Interfaces. 10 (2018) 2579425803. https://doi.org/10.1021/ACSAMI.8B08167.

[38] Somayeh Talebzadeh, Florian Forato, Bruno Bujoli, S. A. Trammell, Stéphane Grolleau, Hemant Pal, Clémence Queffélec, D. Andrew Knight, Nonphotochemical catalytic hydrolysis of methyl parathion using core-shell Ag@TiO 2 nanoparticles, $\quad$ RSC Adv. 8 (2018) 42346-42352. https://doi.org/10.1039/C8RA09553A.

[39] D.L. Kuhn, Z. Zander, A.M. Kulisiewicz, S.M. Debow, C. Haffey, H. Fang, X.-T. Kong, Y. Qian, S.D. Walck, A.O. Govorov, Y. Rao, H.-L. Dai, B.G. DeLacy, Fabrication of Anisotropic Silver Nanoplatelets on the Surface of TiO2 Fibers for Enhanced Photocatalysis of a Chemical Warfare Agent Simulant, Methyl Paraoxon, J. Phys. Chem. C. 123 (2019) 19579-19587. https://doi.org/10.1021/ACS.JPCC.9B04026.

[40] J.B.G. Filho, C.G.O. Bruziquesi, R.D.F. Rios, A.A. Castro, H.F.V. Victória, K. Krambrock, A.A.P. Mansur, H.S. Mansur, R.D. Siniterra, T.C. Ramalho, M.C. Pereira, L.C.A. Oliveira, Selective visible-light-driven toxicity breakdown of nerve agent simulant methyl paraoxon over a photoactive nanofabric, Appl. Catal. B Environ. 285 (2021) 119774. https://doi.org/10.1016/J.APCATB.2020.119774.

[41] D. Paramelle, A. Sadovoy, S. Gorelik, P. Free, J. Hobley, D. G. Fernig, A rapid method to estimate the concentration of citrate capped silver nanoparticles from UV-visible light spectra, Analyst. 139 (2014) 4855-4861. https://doi.org/10.1039/C4AN00978A.

[42] J.L. Wang, R.A. Ando, P.H.C. Camargo, Investigating the Plasmon-Mediated Catalytic Activity of AgAu Nanoparticles as a Function of Composition: Are Two Metals Better than One?, ACS Catal. 4 (2014) 3815-3819. https://doi.org/10.1021/CS501189M.

[43] L. Zhao, C. Deng, S. Xue, H. Liu, L. Hao, M. Zhu, Multifunctional g-C3N4/Ag NPs intercalated GO composite membrane for SERS detection and photocatalytic degradation of paraoxon-ethyl, Chem. Eng. J. 402 (2020) 126223. https://doi.org/10.1016/J.CEJ.2020.126223.

[44] P. Han, T. Tana, S. Sarina, E.R. Waclawik, C. Chen, J. Jia, K. Li, Y. Fang, Y. Huang, W. Doherty, S.E. Bottle, J. Zhao, H.Y. Zhu, Plasmonic silver nanoparticles promoted sugar conversion to 5-hydroxymethylfurfural over catalysts of immobilised metal ions, 
$\begin{array}{llllll}\text { Appl. } & \text { Catal. } & \text { B } & \text { Environ. } & 296 & \text { (2021) }\end{array}$ https://doi.org/10.1016/J.APCATB.2021.120340.

[45] A.J. Vincenzo Balzani, Paola Ceroni, Photochemistry and Photophysics: Concepts, Research, Applications, 2014.

[46] A.P. Betancourt, D.Y. Goswami, V.R. Bhethanabotla, J.N. Kuhn, Scalable and stable silica-coated silver nanoparticles, produced by electron beam evaporation and rapid thermal annealing, for plasmon-enhanced photocatalysis, Catal. Commun. 149 (2021) 106213. https://doi.org/10.1016/J.CATCOM.2020.106213. 